\title{
La visibilidad de la mujer a través las capitulaciones matrimoniales del mundo rural del norte de Aragón (siglos XVI- XVIII) $)^{1}$
}

\section{The visibility of women in the context of pre-nuptial agreements in rural northern Aragon $\left(16^{\text {th }}-18^{\text {th }}\right.$ centuries)}

Encarna JARQue MARTínEZ

Universidad de Zaragoza

ejarque@unizar.es

http://orcid.org/0000-0001-6288-9413

José Antonio Salas AusÉns

Universidad de Zaragoza

jasalas@unizar.es

http://orcid.org/0000-0002-4579-7442

Fecha de recepción: 23-03-2020

Fecha de aceptación: 16-07-2020

\section{RESUMEN}

Tradicionalmente se ha concedido un papel subordinado a la mujer en las capitulaciones matrimoniales, documento básico en la regulación del régimen económico de la familia. Sin embargo, no eran raras las ocasiones en que la mujer alcanzaba protagonismo. El examen de varios centenares de capitulaciones del Alto Aragón nos ha permitido sacar a la luz esa realidad. Son muchos los casos en que sus progenitores u otros familiares la eligen como heredera, no siendo óbice la existencia de hermanos varones. Protagonismo también en las capitulaciones pactadas mediante la figura del agermanamiento, en el que la mujer aportaba la herencia y el varón la dote. Finalmente, protagonismo gracias a la viudedad foral, a la que se podía renunciar y que en ocasiones era sustituida por el "año de manto", figura semejante al any de plor catalán y valenciano.

Palabras clave: Mujer, herencia, matrimonio, viudedad

Topónimos: Aragón

Periodo: Edad Moderna

1 El presente trabajo se ha realizado en el marco del proyecto de investigación HAR 2016-75899P del ministerio de Economía y Competitividad y del grupo de investigación de referencia H01_17R del Gobierno de Aragón. 


\section{ABSTRACT}

Traditionally, a subordinate role has been assigned to women in pre-nuptial agreements, a basic document in the regulation of a family's economy. However, it was not unusual for women to play a leading role. This was due to the predominance in the Alto Aragón region of the "unique heir" law. Examination of several hundred pre-nuptial agreements in the Alto Aragón region has revealed that reality. There are many cases in which her parents or other relatives chose a daughter as heiress, in spite of the existence of male siblings. This female protagonism can also be seen in as well in agreements negotiated in accordance with the system of "agermanamiento", in which the woman contributed the inheritance and the man the dowry. Finally, women achieved a leading role thanks to foral widowhood (Aragonese law), which was sometimes substituted in the Alto Aragon region by the "año de manto" (year of mourning), a similar concept to the any de plor in the Catalonia and Valencia regions.

Key words: woman, inheritance, marriage, widowhood,

Toponyms: Aragon

Period: Modern Age

\section{INTRODUCCIÓN}

A través del análisis de varios centenares de capitulaciones matrimoniales se pretende estudiar la presencia y protagonismo de la mujer a la hora de formar una familia. Tradicionalmente se le ha concedido un papel subordinado, pero el caso altoaragonés presenta ciertas especificidades a tener en cuenta. En primer lugar, una común a todo el territorio aragonés, la legislación que aseguraba a las contrayentes la posesión de los bienes aportados al enlace y los obtenidos posteriormente por herencia y el derecho al usufructo del patrimonio familiar al quedar viuda. En segundo lugar, el peculiar sistema de transmisión de bienes de padres a hijos en el Altoaragón, que, a diferencia del resto del territorio aragonés, estaba basado en el heredero único, pero con total libertad de los padres para escoger entre su prole, no siendo excepcional que la elección recayera en una hija.

En ese sentido, son varios los elementos que dotan al sistema de transmisión de bienes del Altoaragón de cierta especificidad comparados con los que se han conocido para otros ámbitos, tanto de zonas llanas aragonesas donde predomina el reparto igualitario, como de áreas montañosas como pudieran ser la vecinas regiones del otro lado de los Pirineos y las aledañas comarcas del norte de Cataluña y Navarra.

Como en todas partes, las vías usuales de cambio de bienes de unas manos a otras eran la compraventa o la transmisión del patrimonio a través de los testamentos o de los contratos matrimoniales. Durante el Antiguo Régimen, todo ello contaba en los distintos territorios hispanos con algún tipo de norma legal que en general seguiría vigente hasta la promulgación del Código Civil en 1889.

En el reino de Castilla el marco legal de la trasmisión de la propiedad de padres a hijos, regulado por las Leyes de Toro, se mantendría prácticamente sin cambios. La herencia se dividía en cinco partes, cuatro de ellas a distribuir obligatoriamente entre los hijos y nietos. De éstas, había que repartir dos tercios a partes iguales entre hijos e hijas, pudiendo mejorar a cualquiera de ellos con el otro tercio; el quinto restante era de libre disposición del testador, para emplearlo como quisiera. En las Partidas se estipulaba que no se pudiera acumular el quinto y el tercio en la misma persona, pero las leyes de Toro abrieron la posibilidad a hacerlo (Gacto, 1984: 54).

En la Corona de Aragón y en Navarra, en cambio, a grandes rasgos se reconocía la posibilidad de dejar la herencia en una sola persona, aunque había notables diferencias en los distintos territorios. En Cataluña, como heredero "se elige al hijo varón primogénito y 
sólo a la hija primogénita — pubilla—cuando no hay varones" (Ferrer Alós, 2006: 73). Había sin embargo que reservar parte de los bienes para repartir igualitariamente entre todos los hijos, la legítima, que desde las Cortes de 1585 quedó fijada en un cuarto.

En Valencia se daba entera libertad a los padres para optar por el reparto hereditario o igualitario: "Por lo pare o la mare liberament deixar sos bens a sos fills, instituintlos en parts yguals o desiguals, havent pagar los deutes" (Tarazona, 1580: 263). El amplio margen de maniobra que otorgaban los fueros se tradujo en la práctica en un predominio del sistema igualitario. Los fueros permitían la división igualitaria del patrimonio, al menos entre los hijos varones, pero las estrategias familiares tendían a revertir el fenómeno, procurando mantener la herencia de la tierra lo menos dividida posible. Las hijas solían quedar excluidas de la herencia de bienes raíces compensadas con la dote, forma de exclusión femenina, pero a la vez aporte decisivo en el momento de formación de la nueva empresa familiar (Furio, 1998: 31-33). Con la publicación de los decretos de Nueva Planta, que supusieron la supresión de la legislación valenciana, la transmisión de bienes de padres a hijos pasó a regularse como en el reino de Castilla.

Al igual que en Valencia, los fueros aragoneses permitían a los padres repartir los bienes entre los hijos con entera libertad. Podían dejar los bienes en un solo descendiente, hombre o mujer, o hacer un reparto igualitario con la única limitación de dejar una legítima, que en este caso era meramente simbólica: cinco sueldos en dinero y otros cinco en tierras comunes. En el reino de Navarra regían las mismas normas que en Aragón.

Pero bajo el paraguas legal de cada territorio se daban profundas diferencias debidas a múltiples factores como la pervivencia de privilegios forales, caso en el reino de Castilla, de Vizcaya o Guipúzcoa, donde con ligeras variantes, frente al reparto igualitario consagrado en las Partidas y en las leyes de Toro, el padre podía elegir como heredero a cualquiera de sus hijos e hijas, o caso asimismo de Galicia donde la costumbre distorsionaba lo previsto en la legislación mediante procedimientos como la donación intervivos o mandas testamentarias por vía de ventaja (Fernández Cortizo, 2002: 278 y ss.). En realidad, en el territorio hispano, al igual que en el resto del continente europeo, la ley dejaba siempre resquicios más o menos amplios para que las costumbres locales pudieran perdurar o para que la obviaran situaciones familiares particulares.

No era este el caso de Aragón y Navarra, donde la ley, que consagraba la libertad en materia de herencia, permitía que coexistieran un reparto de bienes igualitario entre los hijos con otro de heredero único.

Varios eran los momentos en que podía hacerse la transmisión de la propiedad de padres a hijos. Según la costumbre del lugar o familiar había que esperar al momento de cumplirse las disposiciones testamentarias o, caso de no haberlas habido, al fallecimiento de aquéllos. Otras veces las donaciones eran intervivos, normalmente, aunque no siempre, en el momento del matrimonio de cada uno de los hijos. En este último caso la transmisión se regulaba a través de las capitulaciones matrimoniales.

\section{LA FUENTE: CAPITULACIONES MATRIMONIALES}

La base documental para el presente trabajo han sido capitulaciones de Jaca y la Jacetania —213 capitulaciones—, Valle de Tena -85-, Alto Gállego —91—, Somontano oscense - 519 - Somontano barbastrense -112-, Sobrarbe -105-y Ribagorza - 78(Gómez de Valenzuela, 2003a, 2003b, 2006, 2009, 2010, 2013, Gómez de Valenzuela y Navarro, 2013).

Sabido es que por capitulación matrimonial se entiende el acuerdo celebrado por la pareja con el objeto de pactar el régimen económico de su matrimonio. Conocida ya desde la Alta Edad Media, desde los primeros momentos adquirió una estructura formal bien definida dividida a grandes rasgos en tres apartados: 
En primer lugar, tras el encabezamiento en el que se precisaba la fecha, el notario autorizante y los sujetos intervinientes en la misma - los contrayentes y en la gran mayoría de los casos los familiares más cercanos-, se indicaban los bienes que cada cónyuge o familia aportaba en ayuda y contemplación del matrimonio, señalando el momento o momentos de la entrega.

En segundo lugar, se indicaban las condiciones a que se sujetaba la entrega de dichos bienes, señalando como regla general que debían recaer posteriormente en los hijos o, a falta de éstos, retornar a la familia que los hubiera aportado. Se aclaraban también las responsabilidades sobre posibles deudas preexistentes, el reparto de los bienes adquiridos durante el matrimonio en el momento de su disolución, el aumento de dote si lo había, cláusulas relativas a los gastos de la boda, tratamiento de los padres, viudedad, etc.

En tercer lugar, se solía observar que en lo pactado, salvo indicación expresa, se estaría a lo que marcara la ley, concluyendo con que cada parte se comprometía a cumplir con lo acordado, poniendo como garantía todos bienes y sitios "habidos y por haber" (Bayod, 1995: 60).

En las capitulaciones manejadas relativas al Alto Aragón se hacen visibles multitud de detalles en los que está presente la mujer. Nos centraremos en cinco cuestiones básicas: la presencia femenina en el acto de capitular, el carácter de su aportación en el momento de formar la familia, los compromisos adquiridos por el futuro esposo y, según los casos, por su familia, el régimen económico del nuevo núcleo y la situación de la mujer en el momento de disolución del matrimonio por muerte del cónyuge.

El resultado de los datos obtenidos en principio sería el esperado:

1. Al igual que ocurría en otros territorios, en el contenido de las capitulaciones intervenían factores diferentes: por supuesto la legislación a la que siempre se hace referencia en los textos, pero también los contrayentes, sus familias, la costumbre o el consenso social (Beaur, 2011). De la misma forma que en todos territorios y con mayor frecuencia en los de heredero único, el novio acudía ante el notario acompañado por el padre, en ocasiones también por la madre y siempre por ésta si había quedado viuda. En caso de que los progenitores hubieran fallecido, si el titular de la casa era el novio, solía acudir solo y si se trataba de un segundón, le acompañaba el hermano heredero, que era quien le aseguraba los recursos a aportar al enlace. Lo mismo ocurría en el caso de las novias en quienes la ausencia de los padres era suplida por el hermano heredero o por un familiar cercano - tío o abuelo-. No eran frecuentes las ocasiones en que la novia capitulaba sola: 62 casos entre los 519 contratos matrimoniales del Somontano oscense. En casi todos estos se trataba de viudas que aportaban la dote recibida en su anterior matrimonio, incrementada total o parcialmente con el escrech comprometido por el difunto marido en su capitulación.

2. También dentro de lo esperado, el carácter de los bienes llevados al matrimonio por los contrayentes. Mientras en el caso de los novios predominaban los bienes raíces, en el de las novias lo más frecuente eran las aportaciones en dinero acompañadas de un ajuar más o menos cumplido. 
Tabla 1. Aportaciones de los contrayentes en las capitulaciones (en \%)

\begin{tabular}{|c|c|c|c|c|}
\hline Genero & $\begin{array}{c}\text { Aportación } \\
\text { principal }\end{array}$ & $\begin{array}{c}\text { Pirineos } \\
\mathbf{( 5 7 2 )}\end{array}$ & $\begin{array}{c}\text { Somontano } \\
\mathbf{( 6 3 1 )}\end{array}$ & $\begin{array}{c}\text { Centro del valle del } \\
\text { Ebro (814) }\end{array}$ \\
\hline Varones & Heredero universal & 61 & 56 & 0,5 \\
\hline Mujeres & $31^{\prime} 8$ & 25 & 3 \\
\hline Varones & Tierras o ganado & $7^{\prime} 6$ & $6^{\prime} 7$ & $28^{\prime} 7$ \\
\hline Mujeres & & $2^{\prime} 1$ & $5^{\prime} 2$ & $37^{\prime} 5$ \\
\hline Varones & Dinero & 26 & $34^{\prime} 6$ & $13^{\prime} 1$ \\
\hline Mujeres & & $64^{\prime} 8$ & $68^{\prime} 8$ & $53^{\prime} 8$ \\
\hline Varones & Otros & $5^{\prime} 4$ & 5 & $54^{\prime} 4$ \\
\hline Mujeres & & 1 & 1 & $5^{\prime} 7$ \\
\hline
\end{tabular}

La tabla, elaborada a partir de los datos de 2017 capitulaciones matrimoniales de los siglos XVI-XVIII, de ellas 572 de los valles pirenaicos y la Jacetania, 631 de los Somontanos oscense y barbastrense y 814 de la capital aragonesa, deja ver la diferencia en las aportaciones de unos y otros, a la vez que evidencia el contraste entre el Alto Aragón, de predominio de heredero único, y el centro del valle del Ebro, de claro predominio del reparto igualitario. Queda manifiesto asimismo el mayor peso que las aportaciones en dinero tienen las mujeres en este caso en las tres zonas reflejadas.

3. En la mayoría de los contratos los bienes raíces se transmitían indivisos a un solo hijo que a cambio contraía la obligación de convivir con sus progenitores, sometido a su autoridad y obligado a respetar su condición de señores mayores, a mantenerlos hasta su muerte y a dotar a los demás hermanos y hermanas con unos recursos acordes al valor del patrimonio familiar - "al poder de la casa"- cuya valoración en muchos casos era decidida por el consejo familiar. En el caso de las hijas, la cuantía de la dote se fijaba en su capitulación matrimonial, pactándose entonces las condiciones de entrega, por lo general en varios plazos. Las propias capitulaciones dejaban entrever la frecuencia de los incumplimientos, ya que en las mismas solía preverse que al morir uno de los cónyuges la recuperación de la dote por parte del supérstite o de sus herederos se haría efectiva en los mismos plazos en que la había recibido el esposo.

4. Una de las características sistemáticas de las capitulaciones era la inclusión de cláusulas que pretendían dar salida a situaciones imprevistas como el fallecimiento del heredero sin hijos o con hijos menores, con soluciones distintas: el retorno de la herencia a los padres del fallecido, el matrimonio en casa del cónyuge supérstite o incluso el nombramiento de un nuevo heredero por parte del consejo de familia o junta de parientes y en ellas se otorgaba un papel importante a la mujer, tanto si era la que aportaba la dote, como cuando llevaba la herencia de sus padres (Costa, 1981: 71-102; Salas Auséns, 2015).

Sin embargo estas regularidades obvian una rica casuística en la que la mujer alcanza un claro protagonismo 


\section{MUJER HEREDERA}

Aunque se ve una clara preferencia por el varón a la hora de escoger heredero, en el Altoaragón no puede pasarse por alto la existencia de otras alternativas, hecho constatado asimismo en Navarra, el País Vasco y al otro lado de los Pirineos centrales y occidentales, donde no era raro que la mujer fuera la beneficiaria de la herencia familiar, caso del País Vasco francés, donde regía el derecho de primogenitura por el cual heredaba el mayor independientemente de su sexo (Lafourcade, 1999: 168-169). Las razones para que la mujer recibiera el patrimonio podían ser muchas y en el caso del Altoaragón no diferían mucho de las encontradas para los hidalgos guipuzcoanos:

la oportunidad y capacidad de la persona para hacerse cargo de la casa; la precariedad económica que obligaba a buscar un matrimonio conveniente para saldar posibles deudas, la inclinación de los padres por uno de los hijos o hijas en especial; la adecuación de la persona en relación con las obligaciones que la casa tiene en el seno de la comunidad; la oportunidad de hacer un casamiento que sea del agrado de los padres y de la conveniencia de la casa; la edad del resto de los hermanos; en definitiva, la situación de la casa y las oportunidades concretas de cada uno de los hijos e hijas (Aragón Ruano, 2011: 32).

En las distintas capitulaciones recogidas por Gómez de Valenzuela, en el valle de Tena, la Jacetania y el alto Gállego el porcentaje de herederas en las capitulaciones llegó al 39 '9 \%, proporción que en el caso del Somontano cayó hasta el 24'2 \%². En 76 de las 409 capitulaciones de los años 1578-1634 recogidas por los notarios de Loporzano, localidad del Somontano oscense fue la mujer la que aportó bienes raíces, en la mayoría de los casos donados por sus progenitores o el superviviente de ellos, pero también por hermanos, otros familiares e incluso hijos.

En uno de cada cinco casos, la herencia del patrimonio familiar había recaído en una mujer y las circunstancias que en tal condición acudía al matrimonio eran muy variadas: viudas con hijos que aportaban el patrimonio familiar, caso de Martina Bescós en su enlace con Juan Escario. Con hijo e hija pequeños de su anterior matrimonio, la pareja se obligaba a criar al varón hasta los 14 años y darle 200 sueldos, y a la niña a sustentarla hasta que se casara, dotándola con una cuantía que no se especificaba3; más raras las cesiones de la herencia a la madre por parte de su hijo. Detrás estaba la imposibilidad de gestionar el patrimonio, fuera por su minoría de edad o por haber iniciado estudios, pero su cesión solía tener contrapartidas, caso de Gracia Laguna, cuyo hijo Miguel de Cera la condicionaba a que le cuidara a él y a sus hermanas durante los siguientes seis años ${ }^{4}$. Tampoco era frecuente que el patrimonio llevado por una mujer a su enlace matrimonial procediera de un hermano. Como en el ejemplo anterior, la causa podía ser la culminación de estudios, como ocurrió a Isabel Barrio cuyo hermano Juan estudiaba en el seminario de Huesca ${ }^{5}$, o un problema físico, cuestión reflejada en la capitulación matrimonial de Susana Ximénez, vecina de Puibolea, con Demetrio Rodrigo. Los padres de Susana y de su hermano Diego habían muerto sin testar, por lo que la herencia era a partes iguales, pero Diego era ciego y cedía su parte a la hermana aunque con distintas condiciones entre ellas mantenerle en su casa de por vida y si la convivencia era imposible buscarle alojamiento y entregarle anualmente tres cahices de trigo, cien sueldos y un nietro de vino. No acababan aquí los

2 Porcentajes obtenidos a partir de Ramiro Moya y Salas Auséns, 2013, pp. 37 y 38.

3 Archivo Histórico de la Provincia de Huesca (AHPH), Pedro del Campo, 1599, fol. 282.

4 AHPH, Miguel de Mur, 1588, fol. 18.

$5 \mathrm{AHPH}$, Pedro del Campo, 1599, fol. $91 \mathrm{v}$. 
requisitos con los que Diego cedía sus bienes a su hermana y así se estipulaba que "en casso que Dios nuestro señor quisiera usar de su acostumbrada misericordia con el dicho Diego Ximénez de bolvelle la vista corporal", le tendrían que entregar en dos plazos la cantidad de 1400 sueldos jaqueses. La última clausula establecía que, si Susana moría sin descendencia, Diego recuperaría su parte de la herencia paterna ${ }^{6}$.

Circunstancias distintas podían estar detrás de las herencias a mujeres provenientes de otros familiares como tíos o abuelos. Como en los casos anteriores, la herencia quedaba supeditada al cumplimiento de ciertas cláusulas, como la habitual de reservarse señores mayores usufructuarios de por vida, caso de Felipe Calvo y Ana Ferrer, tíos de Orosia Calvo ${ }^{7}$. Mucho más detalladas las exigencias de los hermanos Pedro y Miguel de Abos, ambos solteros, para dejar sus bienes a su sobrina Isabel de Abos: alojarles en la casa, entregar anualmente a Pedro durante toda su vida un cahiz y medio de trigo limpio, un nietro de vino bueno y un nietro de vinada ${ }^{8}$, que debían conservar en sus toneles hasta que los quisiera vender, darle un asno de pelo pardo de cuatro años, manteniéndolo a su costa, entregarle una ballesta y un cofre que guardaba en la casa y dar entrada en el domicilio a su hermano, Miguel $^{9}$. Si el donante era el abuelo las condiciones de la herencia solían incluir la de mantenerse como señores mayores y usufructuarios de la hacienda, pero sin poder enajenar ni empeñar nada salvo caso de necesidad. Ejemplo de ello la capitulación firmada entre Juan Montaner y María de Gallifo, ambos de la localidad de Aniés. La herencia a María procedía de su abuelo Miguel, con la reserva antes dicha. En este caso la posible enajenación de patrimonio por parte del abuelo debía contar con el visto bueno del vicario y del baile del pueblo. Había otras condiciones, entre ellas la de tener en casa a Rafael, hijo de Miguel, con obligación "de alimentarlo sano y enfermo, médico y medecina, trabajando el dicho en utilidad de la casa" y, si se casaba, dotarle según la calidad de la casa ${ }^{10}$.

Pero lo más frecuente era que la donación a la hija procediera de los padres o de uno de ellos, si el otro ya había muerto, y también aquí las circunstancias podían diferir. En principio pocas novedades aparecían en la capitulación pactada entre María, hija del primer matrimonio de Pedro Escalona, habitantes en Chisagüés aldea de Bielsa, y Miguel Piniés, vecino de Espierba, también aldea belsetana. María aportaba la hacienda paterna y Miguel mercaderías y ganado por valor de 3400 sueldos. El padre, casado en segundas nupcias con Eugenia Falceto, se reservaba ser señor mayor y usufructuario de la hacienda de por vida y, si fallecía antes que su segunda esposa, el usufructo quedaría para ella, también con la consideración de señora mayor, pero previendo que "no queriéndolo ser, le hagan todos buen tratamiento en consideración de haber sido su mujer, si quisiera vivir en la casa con los contrayentes". Pedro Escalona se reservaba además 1400 sueldos para ir entregándolos a razón de 200 sueldos anuales a un hijo varón de su segundo matrimonio, Pedro Jerónimo, a quien tendrían "obligación de sustentarle asta edad de quinze años, trabajando él lo que pudiere en dicha casa y a beneficio della". También obligaba a la pareja a alimentar a Cecilia y Águeda, hermanas de Pedro Jerónimo, y a dotarlas cuando se casaran según las posibilidades de la casa y la costumbre del lugar. Si Pedro Escalona ya había fallecido, la cuantía de las dotes debía fijarla el consejo familiar, integrado por dos deudos de la parte paterna y otros dos de la materna. La capitulación incluía asimismo

6 AHPH, Juan Alberto Gascón, 1639, fols. 5-9.

7 AHPH, Francisco Deza, 1702, fols. 182-187.

8 En el Alto Aragón se denominaba vinada a un vino de peor calidad obtenido de la mezcla de agua con las brisas del vino prensado (Castelló Puig, 1982: 49).

9 AHPH, Miguel de Mur, 1585, fol. 291,

10 AHPH, Pedro Luis Santafé y Otamendi, 1669, fols. 40 v. y ss. 
varias cláusulas en previsión de que los contrayentes murieran dejando hijos menores de edad que no pudieran sacar adelante la hacienda sin riesgo de menoscabo. En ese caso, dos deudos de cada parte, con el propio Pedro Escalona, si todavía viviera, debían disponer lo que mejor les pareciera para la conservación de la casa "aunque sea pribando a los hijos o hijas de la universal herencia de dichos bienes"11.

Había capitulaciones en las que las condiciones se imponían, no a la hija heredera, sino al yerno, como ocurrió en la capitulación entre Bartolomé Mur, de Salas Altas, y Juana Argelo, de Ola. Él aportaba los 1000 sueldos, ella la hacienda de sus progenitores que, según el uso, se reservaban ser señores mayores y usufructuarios de por vida. Las exigencias para el yerno eran la de dar 200 sueldos a un hermano de Juana, mantener en la casa a una hermana y dotarla de acuerdo al poder de la casa y pagar las honras fúnebres de los suegros. Se añadía en la capitulación que, si uno de los donantes fallecía y el otro volvía a contraer matrimonio, tenía que salir de la casa ${ }^{12}$.

Características distintas respecto de las capitulaciones son aquellas, en las que aun habiendo hijos varones, la herencia pasa no al primogénito sino a otros miembros de familia - padres, hermanos o hermanas, sobrinos o incluso al consejo familiar- como heredero fideicomisario a condición de, llegado el momento, designar nuevo heredero preferentemente mujeres. Son muchos los ejemplos en esta línea. Sirva la capitulación pactada en 1705 entre Juan Francisco Orduña y Miguela Martínez, ambos vecinos del pueblecito de Lorbes, próximo a Jaca. Él aportaba 3000 sueldos que le entregarían un hermano y un tío, clérigo. A ella, su hermano Pedro Alexos, soltero, le daba la hacienda, reservándose el señorío mayor, pero sin poder enajenar nada. Juan Francisco y Miguela quedaban obligados a alimentarle, calzarle, vestirle y darle las medicinas que precisara, así como pagar sus exequias. A cambio, Pedro Alexos se comprometía a trabajar para la casa, obligación que también se extendía a una hermana menor, Ana, a la que deberían dotar o, caso de morir soltera, "hacer por su alma". Tenían que vivir juntos y, si el hermano salía a servir en otra casa, no podía llevarse nada. Juan Francisco y María en cambio tenían que hacerse cargo de todas las deudas que tenía la hacienda familiar en aquel momento ${ }^{13}$. En este caso parecen haber sido las dificultades económicas el motivo por el que el hermano cedió el patrimonio de la casa a su hermana y al futuro cuñado.

Lo que pudiera parecer una serie de casos particulares tiene un fondo común: la búsqueda de la pervivencia de la casa, evitando su fragmentación en el momento de la transmisión de bienes de padres a hijos. La respuesta lógica era la de la concentración de los bienes raíces en un heredero, pero a la vez dejando a los donantes total libertad a la hora de elegir al beneficiario que, en no pocas ocasiones, aun habiendo varones, sería una mujer. En la amplia casuística que se da en el Altoaragón en la elección de la mujer como heredera sin duda tienen que ver distintos factores. De un lado la total libertad de los padres en el momento de transmitir el patrimonio, reconocida en el fuero "De testamentis civium et aliorum hominum Aragonum" aprobado en las Cortes de Alagón del año 1307, de alcance limitado en esta fecha a los nobles pero extendido a todos los súbditos aragoneses en las cortes de Daroca celebradas cuatro años más tarde (Savall y Penen, 1866: 242) ${ }^{14}$ y de otro el aludido principio "standum est chartae" —estar a la carta, estar a lo pactado—,

11 AHPH, Gregorio Cebollero, 1663, fol. 70 v.-75.

12 AHPH, Miguel de Mur, 1587, fol. 253.

13 AHPH, José Araguás, 9/7/1705, pp. 151 v.-154 v.

14 "De voluntate et consilio Curiae, perpetuo duximus statuendum, quod de caetero omnes Cives et omnes alii homnes Villarum et Villariorum aragonum possint in suis testamentis unum ex filiis. Quem voluerint, haeredem facere". 
que permitía introducir cualquier tipo de cláusula en los contratos entre particulares, en este caso en las capitulaciones matrimoniales, sin atender a lo que establecieran los fueros (Moreu, 2009). Esta amplia libertad permitió la coexistencia de dos modelos diferentes de transmisión generacional de bienes: el reparto igualitario, que normalmente se contemplaba en los testamentos y que se daba en preferentemente desde la ribera del Ebro hacia el sur de Aragón y el de heredero único dominante en el Alto Aragón. El principio "standum est chartae", daba carta blanca a los particulares para introducir cualquier cláusula en los contratos entre particulares o, caso de las capitulaciones matrimoniales, entre las familias de los contrayentes, que aprovechaban este tipo de acuerdo. Una lo hacía con la pretensión de salvaguardar la continuidad de la casa con los bienes raíces; la otra, cuya aportación solía ser una dote en dinero, incluyendo en el documento todo tipo de cautelas para asegurar su recuperación en caso fallecimiento de la persona dotada, pero sin que hubiera limitación alguna ni para la disposición de los bienes, ni para la elección de quien fuera a disfrutarlos. Era la costumbre la que marcaba el camino a seguir, todo en aras del objetivo buscado, la perduración de la casa.

\section{LA MUJER Y EL AGERMANAMIENTO}

Pero esa continuidad sólo quedaba asegurada si se disponía de mano de obra para sacarla adelante. El futuro marido, que aportaba una dote en dinero, debería hacerse cargo de la explotación lo que le daba cierta posición de fuerza a la hora de pactar las condiciones de la capitulación. En estos casos lo habitual era acordar un régimen de bienes, característico del Altoaragón y distinto de la capitulación a hermandad recogida en los fueros, pactada con gran frecuencia en la capital aragonesa, donde durante los siglos XVI y XVII iba a ser el modelo preferido de regulación de los bienes conyugales, al punto de alcanzar un porcentaje del 55'7\% (Ramiro Moya y Salas Auséns 2013: 47). La hermandad foral consistía básicamente en la puesta en común de todos los bienes aportados por los contrayentes y de los gananciales generados durante el tiempo de vida conyugal. A su finalización, todo debía repartirse a partes iguales entre el supérstite y los herederos del fallecido "desde la ceniza hasta la escoba". El agermanamiento altoaragonés también contemplaba la puesta en común de los bienes aportados por cada contrayente al matrimonio. La diferencia con la hermandad foral estribaba en que en el momento de disolución del mismo por fallecimiento de uno de los dos cónyuges, "el que sobrevive se hace dueño absoluto de los bienes que poseyeron en común durante el matrimonio, lo mismo que de los que fueron de pertenencia de cada uno" (Costa, 1991: 232). De un total de 341 capitulaciones firmadas ante los notarios de la localidad altoaragonesa de Loporzano que ofrecen datos sobre el régimen de bienes hay 66 casos de agermanamiento (Salas Auséns, 2015: 248).

Al igual que en el caso de la hermandad foral, el agermanamiento solía ser la opción de sociedad conyugal elegida por aquellas parejas de escasos y parecidos recursos, pero en algunas zonas del Altoaragón también se daba cuando los padres de la novia, mayores o con hijos de corta edad, en ambos casos sin capacidad para gestionar el patrimonio, le dejaban la casa con sus campos y el novio aportaba, aparte de una dote en dinero, justo lo que más precisaba la familia de ésta, fuerza de trabajo. Esta situación daba lugar a lo que podríamos denominar hermandad conyugal o "agermanamiento en diferido", cláusula por la que el pacto de hermandad no entraba en vigor en el momento del matrimonio, sino que se demoraba durante un tiempo que podía prolongarse hasta diez años. Era una de las salidas a situaciones en las que el patrimonio aportado por la familia de la novia era muy superior a la dote con que acudía el varón, por lo general un segundón. Para la familia o para la novia el agermanamiento suponía la posibilidad de asegurarse su supervivencia y para el futuro esposo, la oportunidad de acceder a los bienes raíces que su condición de segundón 
le había denegado. Pero al mismo tiempo había que evitar que cualquier imprevisto que llevara a un fallecimiento temprano de la novia, pudiera poner el patrimonio de la casa en manos de un recién llegado. El agermanamiento en diferido daba tiempo a la presencia de hijos, limitando el riesgo de que pudiera producirse esa situación.

La capitulación pactada entre Bernat de Mur, de Salas Altas, y la familia de Juana Argeló, de Ola, es un buen ejemplo: Mur aportaba 1000 sueldos y los padres de Juana, con la reserva habitual de quedarse como señores mayores hasta el fin de sus días, le daban la herencia. Tras varias cláusulas, unas habituales en este tipo de contratos -alimentar y dotar a Pedro y Martina, hermanos de la novia, siempre que trabajaran en provecho de la casa-, otras infrecuentes - vetar el matrimonio de los padres de la novia en caso de que uno de ellos quedara viudo, lo que retardaría la plena posesión de la hacienda a la pareja-, se acordaba "que dentro de diez años, tubiendo hijos y no tubiendo hijos entre agermanamiento"15. En caso de que uno de los novios falleciera antes que el pacto entrara en vigor, quedaba nulo el acuerdo y el supérstite y los herederos del fallecido retirarían lo que había aportado cada parte.

En la capitulación pactada entre Juan Pradel y Petronila Bernués, soltera, ambos de la localidad de Lupiñen, el agermanamiento se haría efectivo cinco años después de la fecha del matrimonio, pero la condición para que se validara nada tenía que ver con las habituales. En esta ocasión sólo sería efectivo y siempre y cuando el novio cumpliera con el compromiso de edificar una casa en el solar donado por un hermano de Petronila:

Ittem es pactado y concordado entre las dichas partes que el dicho Juan Pradel haya de edificar dentro tiempo de cinco años del presente día ... en el patio que está tratado le ha de dar dicho Juan Bernués ... una casa habitable y si dentro de dicho tiempo no la edificare, es pactado que los dicho Juan Pradel y Catalina Bernués de aquel día en adelante que fenecidos serán los cinco años dentro los quales se ha de edificar la casa se hayan de hermanar y hacer hermandad, assí de los bienes que de presente tienen y trahen como los que de aquí adelante tendrán ${ }^{16}$.

Un matiz distinto tenía el agermanamiento pactado entre María Bembay, viuda, con el francés Juan de Sot. Él llevaba sus bienes y ella los que le había dejado en herencia su marido, de quien tenía un hijo. El problema en el caso de Juan de Sot y María Bembay radicaba en los posibles derechos que pudiera tener Juan Panart, hijo del primer matrimonio de María. Dado que la casa en que iban a vivir la había heredado su madre de su primer marido con la condición de cuidar de su hijo, los futuros contrayentes se comprometieron a proporcionarle lo necesario hasta que cumpliera 12 años de edad y a darle en tres tandas anuales la suma de 500 sueldos, a cambio de que renunciara a favor de ellos a los bienes paternos ${ }^{17}$.

En este tipo de pactos matrimoniales en que la mujer aportaba la hacienda, lo habitual era que durante los años en que el matrimonio no estaba todavía agermanado el marido recibiera una renta cuya cantidad variaba de unos casos a otros. En el agermanamiento entre Tomasa Cortillas, de Arbaniés y Úrbez Bentué, de La Almunia del Romeral, pactado para iniciarse a los tres años de la boda, la cantidad establecida fue de 180 sueldos anuales "en reconocimiento de sus trabajos"18. Cantidades distintas pero nunca superiores a los 250

15 AHPH, Miguel de Mur, 1587, fols. 253-254.

$16 \mathrm{AHPH}$, Melchor de Arbustante ,1600, fols. 89v-93, -

17 AHPH, Gregorio Cebollero, 1656, fols. 58-60.

18 AHPH, Miguel de Mur, 1585, fol. 90. 
sueldos anuales se pactaban en otras capitulaciones en las que el régimen de bienes era el agermanamiento. Podríamos decir que durante ese tiempo el marido no pasaba de ser un asalariado, eso sí, con la responsabilidad de sacar adelante con su trabajo la hacienda de su esposa.

\section{LA VIUDEDAD FORAL}

Uno de los elementos claves de la capitulación que concernía especialmente a la mujer se refería a la viudedad, con notables diferencias en lo estipulado en los distintos territorios peninsulares (Pimoulier, 2006; Birriel, 2008; Rey Castelao y Rial García, 2008; Rodríguez Alemán, 2008; Bouzada, 1997; Fauve-Chamoux, 1998). En Cataluña y en Valencia la viuda recuperaba la dote aportada al matrimonio y el creix o escrech, donación del marido propter nuptias, y los herederos tenían que mantenerla durante un año —el any de plor - que en todo caso se prolongaba hasta que había recuperado toda la dote y durante el cual debía mantener su viudez (Guillot, 2001: 271-278; Birriel 200: 17-18). En Castilla, se preveía la restitución de la dote y de las arras en caso de no tener hijos, pero, si los había, tan sólo podía disponer de una cuarta parte de las mismas, quedando las otras tres partes para sus descendientes. Además, las Partidas reconocieron a la viuda un específico derecho sucesorio, la llamada cuarta marital de la que podía beneficiarse la viuda pobre que no tuviera bienes dotales, arales ni propios con los que subsistir (Gacto, 1984: 54). Esta diversidad de situaciones la encontramos también en otros ámbitos europeos caso de Francia, donde el código civil de Luis XIV no pudo acabar con los centenares de costumbres consuetudinarias en materia de herencia, muchas de ellas afectando a la mujer (Dousset, 2009) o Italia (Giulodori, 2008).

En Aragón y Navarra los fueros contemplaban el derecho del viudo a usufructuar los bienes del cónyuge fallecido, incluso de aquéllos que éste hubiera enajenado en vida sin el consentimiento del superviviente (Nausia, 2013). El derecho al usufructo tan sólo se perdía ante el cese de la viudedad por unas segundas nupcias o, en el caso de las viudas, si llevaban una vida deshonesta. La viudedad se seguía manteniendo si él cónyuge supérstite profesaba en alguna orden religiosa (Savall y Penen, 1866: 231). La viuda aragonesa en principio quedaba en una condición más favorable que la de otros territorios peninsulares. La norma amparaba al cónyuge superviviente, con independencia de su sexo, pero en la práctica favorecía más a la mujer, tanto en lo tocante al valor de los bienes usufructuados, como al número de posibles beneficiados. Generalmente el valor de los bienes aportados por el novio al matrimonio, como heredero del patrimonio familiar, superaba a los de la novia y además, al incluir tierras de labor, podía generar una renta anual. Por otra parte, al acceder la mujer al matrimonio a una edad más temprana, contraer segundas nupcias en menor proporción que los varones y tener una mayor esperanza de vida eran más las viudas que los viudos. Así lo confirman los datos del censo de Floridablanca: en 544 localidades de los corregimiento de Jaca, Huesca, Barbastro y Benabarre, el $60 \%$ de los 6293 viudos eran mujeres (Salas Auséns, 2012: 1262), proporción mucho mayor que la observada en el resto del territorio aragonés (Jarque Martínez y Salas Auséns, 2020: 201). Pero las hipotéticas ventajas no siempre eran tenidas en cuenta y con gran frecuencia en las capitulaciones matrimoniales altoaragonesas los contrayentes renunciaban de manera explícita a la viudedad foral. Las fórmulas para ello eran varias. En ocasiones, simplemente se expresaba la renuncia a los fueros de Aragón - "el qual matrimonio no es fecho según fuero sino segunt pacto e condiciones siguientes...", se especificaba en el contrato matrimonial firmado en Belsierre en 1525 entre Martín de Baguest y Antonia Sasse ${ }^{19}$. Distinta era la

19 AHPH, Pedro Climent, sin foliar, 21/5/1525. 
fórmula empleada un siglo más tarde en los capítulos pactados en la Pardina, un barrio de Castejón de Sobrarbe, entre Domingo Barbastro e Isabel Sánchez: "an sido hechos y pactados los presentes capitoles matrimoniales con intervención de parientes y amigos de las dos partes no a fuero de Aragón ni costumbre de Cataluña, sino con los pactos y condiciones siguientes"20. La fórmula usada en el Valle de Tena aludía a la costumbre del lugar, repitiendo en la mayoría de los contratos el siguiente texto: "se entiendan y ayan de entender al uso y costumbre de la presente Valle de Tena y conforme sus estatutos y no al fuero de Aragón, al qual renuncian dichas partes por pacto especial"21. Y ya en el siglo XVIII, haciendo prevalecer como en tantas ocasiones el principio del standum est chartae sobre cualquier norma legal, nos encontramos con una nueva fórmula en la que, con las mismas consecuencias que las anteriores, aparecía explícita la mención a Castilla. Es la que aparece en la capitulación firmada en el lugar de Senés de la comarca de Sobrarbe en el matrimonio ya consumado entre Pedro Gistau y María Beguería: "la qual capitulación no es fecha según fueros de Aragón ni leyes de Castilla ni otros reynos, sino con los pactos, vínculos y condiciones infrascriptos y siguientes..."22.

Independientemente de las fórmulas empleadas, lo que nos interesa es ver cuántas capitulaciones se pactaban según los fueros de Aragón y cuantas al margen de los mismos, con renuncia de la viudedad foral, así como las condiciones para suplirla. A diferencia de lo que se estaba practicando en la capital aragonesa donde los contratos matrimoniales acordes con los fueros sobrepasaban el $90 \%$, en el Altoaragón los porcentajes eran mucho más bajos —el $25 \%$ en Jaca y la Jacetania, el 6'2 \% en el valle de Tena, el 3'4 \% en el Alto Gállego, el 9'7 \% en el Somontano oscense y el 11'7\% en el Somontano barbastrense (Ramiro y Salas Auséns, 2013: 47). Entre las 105 capitulaciones de la comarca de Sobrarbe tan solo una decena se pactaron de acuerdo con los fueros de Aragón, tres de ellas a hermandad y de las otras siete en que se reconocía expresamente el derecho a la viudedad foral, una estaba fechada en 1554 y las otras seis eran de principios del siglo XIX. En las demás se hacía constar la renuncia a los fueros pero en parte de ellas con excepción expresa de la viudedad, cuyo disfrute se reconocía al supérstite. La renuncia a la viudedad, muy frecuente en el siglo XVI, fue decayendo en las centurias siguientes. Entre las 105 capitulaciones del Somontano oscense publicadas por Gómez de Valenzuela hay 8 renuncias a la viudedad foral en el siglo XVI, 8 en el XVII y 2 en el XVIII. En cambio, la viudedad no era reconocida en ninguna ocasión en el siglo XVI, 14 veces en las capitulaciones del siglo XVII y 27 en las del XVIII. Una tendencia similar se observa en Sobrarbe: en el XVI, 2 reconocimientos de viudedad foral y 9 renuncias a la misma, en la centuria siguiente, 14 y 26, respectivamente y, en el XVIII, 26 y 3. A notar que ya desde el XVII comienza a utilizarse la renuncia parcial a los fueros: "Se renuncian las ventajas forales el uno al otro viceversa, excepto dono gracioso y derecho de viudedad".

¿En qué situación quedaba la viuda que había renunciado a la viudedad? La casuística aquí también es muy variada: había quienes quedaban como señoras mayores de por vida, normalmente con la salvedad de que debían permanecer como viudas honradas y trabajar para el bien de la casa. Perdían esa condición si volvían a casarse, pero recuperaban la dote en los mismos plazos en que había sido entregada y, en su caso, el escrech o aumento de dote. Podía también darse el caso de que en la capitulación se hubiera previsto que la viuda pudiera casarse sin salir de la casa. Esta alternativa solía contemplarse cuando

20 AHPH, Francisco Sánchez, fols. 45v.-49, 19/5/1608.

21 Archivo de Casa Lucas (Panticosa), Miguel Matías Guillén, año 1697, fols. 39-40.

22 AHPH, Mateo Solans, 1711, fols. 68-73v. 
había hijos pequeños incapaces de trabajar las tierras. Pero este extremo debía constar explícitamente en el documento.

En el supuesto de que los suegros hubieran muerto, también encontramos distintas variantes. Una de ellas es la intervención de un consejo familiar. Fue lo previsto en la capitulación de Pedro Gistau, heredero de sus difuntos padres, vecino de Senés, localidad del Sobrarbe, y María Beguería, de San Juan de Gistau. Pactaban que si él moría antes

con hijos menores de edad e incapazes de poder regir y gobernar los dichos bienes de calidad que aquellos se hubieren de disminuir y perder, en tal casso es pactado y acordado que la dicha contrayente se pueda volver a casar en la cassa y bienes desta dotación ... a conocimiento de dos deudos de cada parte ${ }^{23}$.

En otras capitulaciones era el marido quien, por si fallecía antes que su esposa, le abría la posibilidad de volver a casarse sin abandonar la casa. Así se pactaba en el contrato entre José de Rins y María de Mur y Heredia, ambos infanzones, del lugar de Gistaín:

si se disolviere el presente matrimonio por muerte de el contraiente y le quedaren hijo o hijos, hija o hijas menores de edad que reconozca el contraiente es conveniente que la contraiente se vuelva a casar en la dicha casa, pueda darle el contraiente facultad de hazerlo y firmar dotes sobre los bienes de la presente donación a fin de criar sus hijos y conservar la casa ${ }^{24}$.

En la capitulación de Nicolás Piniés y Teresa Bernad, vecinos de Bielsa, eran sus convecinos Antonio Berastegui, Juan Bernad Quilez, Juan de Buerba y el rector de la Iglesia quienes debían dar la aprobación a un posible nuevo matrimonio de la viuda:

y que en caso de disolverse el presente matrimonio por muerte del contraiente y quedarles hijos menores de edad, que estos no puedan regir y gobernar la casa, que en este caso se da facultad a la contraiente de contraer segundo matrimonio en los bienes de la presente donación con parecer y no sin él de las personas arriba nombradas, todos juntos o la mayor parte"25.

Casarse en casa era la posibilidad que se daba también a Teresa Cornel, del lugar de Anciles, que el día previo a la capitulación había contraído matrimonio con Antonio de Mur, vecino de Serveto. En esta ocasión la posibilidad del casamiento en casa quedaba condicionada a que a la muerte de Antonio quedaran hijos huérfanos. La novedad respecto a otros pactos estribaba en que a Teresa se le ofrecían tres posibilidades. La primera que "con el permiso y aprobación de dos deudos de los más propinquos de cada una de dichas partes pueda dicha contrayente casar en casa del contrayente". Otra alternativa era casarse fuera de la casa. En ese caso podría recuperar la dote en los mismos plazos que la había entregado una vez transcurrido el año de luto. Pero si quería permanecer viuda quedaría como señora mayor y usufructuaria con las condiciones normales: ser viuda honesta y emplear el usufructo, "en compañía, utilidad y beneficio del heredero de dicha casa y demás familia"26.

23 AHPH, Mateo Solans, 1711, fols. 67-73.

$24 \mathrm{AHPH}$, Mateo Solans, 1717, fols. 27-30.

$25 \mathrm{AHPH}$, Antonio Vidaller, 1732, fols. 33-34.

26 AHPH, Pedro Berastegui, 1753, fols. 5v-7. 
Entre las capitulaciones pactadas al margen de los fueros las había realizadas según la costumbre de Cataluña, expresión explicitada abiertamente o deducida a partir de los propios términos del pacto. Aparte de la figura del heredero, con preferencia del varón sobre la mujer y entre aquellos del primogénito sobre sus hermanos, y de la cuantía establecida como legítima para los desheredados, la diferencia más significativa en la norma catalana era la situación en que quedaban las viudas, que tras el any de plor debían abandonar la casa, recuperando su dote, en contraste con el usufructo universal a que los fueros daban derecho a viudos y viudas aragonesas (Mikes, 2017: 183-184).

No son muchas las capitulaciones en que se reconoce expresamente que se han pactado según la costumbre catalana, tan sólo dos entre las 105 de Sobrarbe o seis entre las 112 de la Jacetania. Pero en cambio, en alguna de las comarcas, caso del Somontano oscense, son frecuentes los pactos en que, sin mencionar al principado catalán, se recoge la cláusula del año de manto, idéntica al any de plor. El año de manto se contemplaba en 191 de las 341 capitulaciones realizadas entre 1578 y 1634 por los notarios de la localidad de Loporzano, en que se hacía referencia a la situación en que quedaba la viuda (Salas Auséns, 2015: 248). Y un comportamiento similar venimos comprobando en un nuevo lote de capitulaciones de fines del XVI y principios del XVII de las localidades de Bolea y Pertusa, ambas en la comarca de Hoya de Huesca, en fase de estudio.

Una vez más aparecen en ellas variantes del año de manto. Una era la de dejar elegir a los herederos mantener en casa a la viuda un año o sacarla, proporcionándole alimentos durante ese tiempo, posibilidad contemplada en la capitulación de Jaime Pérez de Olivan, infanzón, e Isabel de Luro, viuda. Uno de los ítems decía:

en caso de disolución del presente matrimonio por muerte del dicho Jayme Pérez de Olibán, sobreviviéndole la dicha Isabel de Luro, su esposa futura, que en tal caso los herederos del dicho Jayme Pérez de Olibán hayan y sean tenidos y obligados de tener y mantener en su casa a la dicha Isabel de Luro, sana y enferma, dándole de comer, beber, vestir y calcar, y médicos y medicinas y todo lo necesario por tiempo de un anyo del día de la muerte del dicho Jayme Olibán en adelante contadero, o si no que le hayan de dar para su sustento del dicho anyo tres cahizes de trigo bueno y mercader, dos nietros de vino bueno de buen sabor y color y cinquenta sueldos dineros jaqueses y que esté en opción y voluntad de los dichos herederos de tener y mantener o darle el sobredicho sustento por el sobredicho tiempo de un anyo ${ }^{27}$.

Otra variante consistía en prolongar el tiempo que podía permanecer en la casa hasta dos o más años, cláusula incluida en la capitulación de Pedro de Ayala, viudo y Agustina Salvador, doncella. Se pactaba

que en tal caso lo herederos del dicho Pedro de Ayala o Miguel de Ayala, mayor, hayan de tener y mantener en su casa a la dicha Agostina Salvador sana y enferma, dándole de comer, beber, vestir y calzar, médico y medicinas y todo lo necesario y esto por tiempo de dos anyos del día de la muerte del dicho Pedro de Ayala en adelante contaderos y esto si la dicha Agostina quisiere vivir y habitar en companya dellos y si no que le hayan de dar en cada un año por el tiempo de los dichos dos anyos seys cahizes de trigo, quatro nietros de vino y cient sueldos dineros jaqueses en cada un año"28.

\section{CONCLUSIONES}

A través de los varios centenares de capitulaciones matrimoniales del Alto Aragón trabajadas, se ha podido claramente percibir el importante papel de la mujer en los sistemas

27 AHPH, Ramón de Nasarre, 1582, fol. 106.

28 AHPH, Ramón de Nasarre, 1582, fol. 46. 
de transmisión de la propiedad en el mundo rural y en la regulación del régimen económico familiar.

Pequeñas pinceladas de un mosaico mucho más complejo, lleno de matices donde, en el marco de unas líneas generales muy difusas, la variedad de situaciones en que encontramos a la mujer es casi inabarcable. Presente a veces en solitario en la capitulación, las más en cambio acompañada de sus familiares más cercanos; aportando preferentemente una dote en dinero y renunciando a cualquier otro derecho sobre los bienes paternos, pero también en no pocas ocasiones heredera del patrimonio familiar, gracias a la total libertad que las leyes aragonesas otorgaban a los padres en la transmisión de la herencia a la búsqueda de la continuidad de la casa, incluso teniendo hermanos varones; pactando un régimen de bienes, la hermandad foral, donde comparte con el marido la propiedad común de los mismos y su partición a medias en el momento de disolución del matrimonio; agermanándose, pero dilatando el comienzo del agermanamiento durante un tiempo prudencial a la espera de descendencia; asegurando la pervivencia de la casa de los suegros tras la muerte del marido con un nuevo matrimonio; renunciando a la viudedad foral y pactando el año de manto de luto, antes de recuperar la dote y, en su caso todo o parte del escrech, o firmando una capitulación respetuosa con la normativa foral y, por tanto, acogiéndose a la viudedad foral, las más de las veces junto a su esposo, más raramente en solitario.

\section{BIBLIOGRAFÍA}

Aragón Ruano, A. (2012), "Mujeres y conflictividad familiar en Guipúzcoa durante en Antiguo Régimen", Obradoiro de Historia Moderna, 21, pp. 29-54.

Baldellou Monclús, D. y Salas Auséns, J. A. (2016), "Noviazgo y matrimonio en Aragón casarse en la Europa del Antiguo Régimen", Revista de Historia Moderna, Anales de la Universidad de Alicante, 34, pp. 79-105.

Baldellou Monclús, D. (2013), "La posición de la mujer ante el matrimonio en las familias aragonesas del siglo XVIII", en J. A. Salas Auséns (coord.), Logros en femenino. Mujer y cambio social en el valle del Ebro, siglos XVI-XVIII, Zaragoza, Prensas universitarias de Zaragoza, pp. 75-110.

Bayod López, M. C. (1995), Sujetos de las capitulaciones matrimoniales aragonesas, Zaragoza, Institución Fernando el Católico, 60.

Beaur, G. (2011), "Le contrat de mariage dans les sociétés européennes. Enjeux familiaux et pratiques de acteurs", Annales de démographie historique, 1, pp. 5-21.

Birriel Salcedo, M. (2008), "El cónyuge supérstite en el derecho hispano", Chronica Nova, 34, pp. 13-44.

Bouzada Gil, M. T. (1997), "El privilegio de las viudas en el Derecho Castellano", Cuadernos de Historia del Derecho, 4, pp. 203-244.

Castelló Puig, A. (1982), "La representatividad del viñedo y su influencia en los aspectos económico-sociales del municipio de Colungo", Argensola, 93, p. 49.

Costa, J. (1981), Derecho Consuetudinario y economía popular en España, Zaragoza, Guara Editorial.

Dousset, Ch. (2009), "Femmes et héritage en France au XVIle siècle", XVIIe. siècle, 3, pp. 477-491.

Fauve-Chamoux, A. (1998), "Vedove de cittá e vedive di champagne nella Francia Preindustriale: aggregato domestico, trasmissione e strategie familiari di sopravivenza", Quaderni Storici, 98-2, pp. 301-322.

Fernández Cortizo, C. (2002), "La tierra de Montes en la época moderna. Permanencias y cambios en una sociedad rural de Antiguo Régimen", Obradoiro de historia Moderna, 11, pp. 247-288. 
Ferrer Alós, LI. (2001), "Apparition, évolution et logique des contrats de mariage en Catalogne (XVI - XIXe siècle)", Annales de Démographie Historique, 1, pp. 23-48.

- (2006), "Propietarios y sistema de heredero único en Cataluña en el siglo XIX", en Xavier Roigé, Familias de ayer, familias de hoy: continuidades y cambios en Cataluña, Barcelona, Icaria, pp. 71-98.

- (2007), Hereus, pubilles i cabalers. El sistema d'hereu a Catalunya, Catarroja, Afers.

- (2014), "Desigualdades de género en el acceso a los derechos de propiedad y sistemas hereditarios en España", Áreas, 33, pp. 35-47.

Furió, A. (1998), "Reproducción familiar y reproducción social: familia, herencia y mercado de la tierra en el país valenciano en la baja Edad Media" en F. García González (ed.), Tierra y familia en la España meridional, siglos XIII-XIX, Murcia, Universidad de Murcia, pp. 31-33.

Gacto Fernández, E. (1984), "El marco jurídico de la familia castellana. Edad Moderna", Historia. Instituciones. Documentos, 11, pp. 37-66.

Giuliodori, S. (2008), "Qué fuentes? ¿Qué cuestiones? Los estudios sobre la capacidad patrimonial de la mujer en Italia durante la Baja Edad Media", Studia Histórica, Historia medieval, 26, pp. 91-109.

Gómez de Valenzuela, M. (2003a), Capitulaciones matrimoniales de Jaca, Zaragoza, Justicia de Aragón.

- (2003b), Capitulaciones matrimoniales y firmas de dote en el Alto Gállego (14281805), Zaragoza, Justicia de Aragón 2003.

- (2006), Capitulaciones matrimoniales del Somontano de Huesca (1457-1789), Zaragoza, Justicia de Aragón.

- (2009), Capitulaciones matrimoniales de la Jacetania (1441-1811), Zaragoza, Justicia de Aragón.

- (2010), Capitulaciones matrimoniales de Barbastro y su Somontano (1459-1775), Zaragoza, Justicia de Aragón.

- (2013), Capitulaciones matrimoniales de Sobrarbe, (1439-1807), Zaragoza, Justicia de Aragón.

Gómez de Valenzuela, M. y Navarro Soto, A. L. (2002), Capitulaciones matrimoniales y firmas de dote en el valle de Tena (1426-1803), Zaragoza, Justicia de Aragón.

Guillot, D. (2001), "Derechos de la viuda en la Valencia foral”, Hispania: Revista española de historia, 61, 207, pp. 267-288.

Jarque Martínez, E. y Salas Auséns, J. A. (2020), “¿Viudedad o segundas nupcias? Opciones diferenciadas en el Aragón moderno", en J. P. Blanco Carrasco, Las segundas nupcias en la Edad Moderna, Madrid, Silex, pp. 281-306.

Lafourcade, M. (1999), "Sistemas de herencia y de trasmisión de la propiedad en Iparralde bajo el Antiguo Régimen", Vasconia, 28, pp. 168-169.

Mikes, T. (2017), "Legislació Històrica de la familia catalana medieval y moderna", Bulleti de la Societat Catalana d'Estudis Historics, XXVII, pp. 163-196.

Moreu Ballonga, J. L (2009), Mito y realidad en el Standum est Chartae, Madrid, Editorial Civitas.

Nausia Pimoulier, A. (2006), "Las viudas y las segundas nupcias en la Europa moderna: últimas aportaciones", Memoria y civilización, 9, pp. 233-260.

- (2013), "El usufructo de viudedad navarro como recurso de supervivencia para las viudas (siglos XVI y XVII)", Iura Vasconiae, 10, pp. 573-596.

Oliveri Korta, O. (2001), Mujer y herencia en el estamento hidalgo guipuzcoano durante el antiguo Régimen, San Sebastián, Diputación de Guipúzcoa.

Ramiro Moya, F. y Salas Auséns, J. A. (2013), "Mujer y transmisión de la propiedad en el 
Aragón moderno", en J. A. Salas Auséns (coord.), Logros en femenino. Mujer y cambio social en el valle del Ebro, siglo XVI-XVII, Zaragoza, Prensas Universitarias de Zaragoza, 2013, pp. 15-75.

Rey Castelao, O. y Rial García, S. M (2008), "Las viudas de Galicia a fines del Antiguo Régimen", Chronica Nova, 34, pp. 91-122.

Rodríguez Alemán, I. (2008), "Opciones matrimoniales de la mujer viuda en Málaga (15641700)", Chronica Nova, 34, pp. 123-157.

Salas Auséns, J. A. (2012), "Preparando la vejez: mujer y capitulaciones matrimoniales en el mundo rural altoaragonés en la Edad Moderna", en M. J. Pérez Álvarez y L. Rubio (eds.), Campo y campesinos en la España Moderna. Culturas políticas en el mundo hispano, León, Fundación de historia moderna, pp. 1260-1261.

- (2015), "Pero si..., y si..., por si... asegurar la pervivencia de la casa en el alto Aragón en la Edad Moderna", Obradoiro de Historia Moderna, 24, pp. 225-255.

Savall, P. y Penén, S. (1866), Fueros, Observancias y Actos de Cortes del Reino de Aragón, Zaragoza, Tipografía Francisco Castro y Bosque.

Tarazona, P. J. (1580), Institution del furs y privilegis del Regne de Valencia eo summarie repertori de aquells, (De Testaments. Tit. XIX), Valencia, Imprenta de Pedro de Guete. 